\title{
"I'm not Typical": A Study Exploring the Effect of Social Comparison and Categorisation by Undergraduates
}

\author{
Julienne McGeough, David McIlroy, Susan Palmer-Conn \\ Liverpool Hope University, United Kingdom \\ Liverpool John Moores University, United Kingdom
}

\begin{abstract}
Widening participation has led to a growth in university places across the Higher Education Sector. Alongside this, there is greater public scrutiny of the quality of both degrees and institutions. Additionally, students have a greater awareness of the potential quality of the institute they are attending via league tables and the annual NSS. While research has been undertaken exploring how students make choices there has been less focus on the experience of students at "lower status" universities. Three focus groups of $N=19$ Psychology students from a North-West university were conducted to discuss issues of identity. Thematic Analysis was used to explore issues of Social comparisons and Identity processes. The main themes to emerge were transitional issues, threats to identity and identity protection as students developed narratives around their perceptions of status of student and institution. Furthermore, "othering" processes allowed exploration of the dual comparison processes when identifying with the institution label. These findings are discussed in relation to enabling students to develop a stronger identity.
\end{abstract}

\section{Introduction}

Widening participation in the UK Higher Education system has been an aim of government from the 1980's onwards [1] supported by various legislative acts such as the Teaching and Higher Education Act 1998 and Higher Education Act of 2004 [2]. These changes have led to a number of differences within HE; increased student numbers, diversification of the student body and an expansion in the universities with degree awarding powers. [3], [4]. Alongside the policy of widening participation has been a focus on transparency of the quality of education offered to students. League tables, often published within national newspapers and available online, allow for easy comparison by potential and current students of one institution to another [5]. It is notable that there is currently little evidence that rankings of institutions are important in the decision making of prospective students [5] however what has been explored is that students at traditional red-brick universities express a sense of privilege derived from the prestige of the institution [4], [6]. Additionally, there is growing evidence that graduating from higher status universities is linked to increased earning power and better job prospects [6]. Research has increased on the economic and political changes within Higher Education [2]. Additionally, some which focuses on the choices made by students when deciding which university to attend [7], [8] there has been little exploration of the experiences of attending new universities. The current paper explores possible comparison processes and outcomes of students at a new university and the impact on their student identity.

\section{The need to compare}

Psychological processes of comparison argue that the need to compare amongst individuals is universal, [9] driven by the need to evaluate selfworth against the perception of others around them. Festinger's Social Comparison Theory suggests that this process can be both upward and downward with feelings of superiority or inferiority as the outcome. However, while Festinger proposes that Social Comparison processes are essential for an individual's need to maintain an accurate self-view further research has been undertaken which explores how individuals also derive their sense of self from groups in society. Social Identity Theory [10] and Self-Categorisation Theory [11] provides an understanding of how the individuals membership of a specific group enhances or lowers their selfesteem. Furthermore, Self-Categorisation Theory posits that the status of groups in society are judged by individuals and it can be concluded that selfesteem protection is motivated by enhancing the ingroup (i.e. their social group) above that of outgroups. It is proposed by the current study that students from post-1992 universities and newer institutions will engage in upward social comparisons. Furthermore, there will be evidence of 
Social Identity and Categorisation processes which results in students displaying in-group enhancements in order to maintain a positive self-image and protect self-esteem.

\subsection{Transition: Increasing vulnerability}

Identity development occurs throughout daily interactions however there are times when questions of who we are become more pertinent. Cinnerella [12] proposes that possible future social identities can be examined within the framework of Social Identity. This study argues that individuals engage in increased cognitive categorizing of potential groups when in a new setting. Surprisingly transitions have been under research from a Social Identity perspective. This seems a surprising oversight given that the prospect of joining a new group would seem to be at the heart of Social Identification and Categorisation. This is possibly due to the focus within Social Identity to develop a theoretical understanding of conflict between groups rather than intra-identity and personal conflict. That identities shift during transitions periods throughout the school career is well established and results in challenges to self-concept [13]. The move into Higher Education brings further challenges with research indicating high drop-out rates for those students who fail to integrate socially [14], [15], [16]. Furthermore, Krause and Coates [17] place the struggle to find one-self and develop a new identity as central to the challenge of successful transition into Higher Education. While it can be assumed that this process will occur at the start of university, the current study also explores transition at the other end of the undergraduate experience. It is proposed that as students prepare to graduate, reflecting on their university days and contemplate the future Social Comparison and Social Identity behavior will emerge.

\subsection{Identity protection processes}

As already stated there is a gap around transition and social identity research, a further issue resulting from a lack of intra-identity research is that of understanding how minority groups negotiate identity threats to protect self-esteem. To fully understand the processes of identity protection, a close consideration of the findings from the research around stigma can be applied. Stigmatisation, defined, by Goffman, [18] is the psychological process, which occurs when an attribute reduces the individual involved from a sense of being whole to that of being to a tainted or discounted. While it has generally been studied within disability populations, there has been research that involves stigmatisation of groups within society based on their religion, HIV status, ethnicity and education. Importantly relationships and social contexts are central to the process of stigmatization [19]. Furthermore, Goffman suggests that there are three forms of social stigma, one of which are "tribal stigmas" and include attributes such as nationality or social background. It is not the claim of the current study to describe students at newer universities as a stigmatized group however there are a number of theoretical processes from stigma research that may usefully be applied to the current study, particularly when considering tribal stigmatisation. Furthermore, this may give a better idea of how identity protection may work with an identity that is confusing.

\subsection{Research Aims}

Transition periods within the current study will provide a lens in which to understand how students process their identity at university, their understanding of the university system and the impact of this on self-esteem. A further aim is to explore whether participants employ identity protection strategies to enhance their sense of self.

\section{Method}

Focus group discussions guided by questions of identity and self-categorisation were conducted with mixed groups of $1^{\text {st }}$ and $3^{\text {rd }}$ year students. Groups ranged from $4-8$ in size $(n=19)$ with males and females' students from University in the North-West of England. It has been argued that focus groups add to the purity and quality of data as participants are able to converse with peers about their experiences, additionally with careful analysis issues of group think can be reduced [20], [21]. Interview questions were loosely developed around an existing social identity questionnaire, which covered the cognitive and affective components of Social Identity. Importantly it allowed for measurement of different social groups closely aligned within a school setting, that is pupil identity and institution identity [22]. A typical question was "would you think it was accurate if you were described as a member of?" Participants were asked to consider questions from a student, institutional and subject perspective.

Thematic analysis has a degree of flexibility that means that not only can the data be used to reflect the reality on the surface of the data but also be used to dissect this surface [23] looking underneath at themes and patterns that emerge. The analysis will take both a deductive theoretical approach as well as inductive which will allow the data to be analysed within Social Identity and Social Categorisation Theories. This technique is supported by Hayes [24] in her paper on theory led thematic analysis. Additionally, template analysis as described by a number of researchers allows for a mixed inductive 
and deductive approach to thematic analysis [25], [26]. Data will be coded at a semantic level; the interpretation of the phenomenological is introduced when previous research is discussed. As the interviews were focus groups, the data was first examined for independently voiced conversation or where it may have been prompted by more vocal group members; these were identified on the transcripts, with the focus on direct answers. The initial round of coding was used to develop a code book which allowed for cross analysis and ensured saturation. Once the coding was complete emerging codes and themes were identified, drawing out interconnections. Disjointed and different themes to that which was expected were also noted. Finally, the codes are examined by reviewing the previous stages and includes a series of reiterations from text to codes and corroboration on existing themes and also to ensure that themes are fully represented within the coding table. Clustering is also a crucial part of this final stage with a final set of core themes emerged.

Participants were recruited via email with the first years receiving a course credit for attending. The groups ranged from 4-8 in number and were composed of first and third years who all were taking Psychology as either a single or joint honours. The institution studied was a previous teacher training college. The institution was granted degree-awarding powers in 2012 and added University to its name 10 years ago.

\section{Results and Discussion}

Four broad themes emerged from the data (Identity Pressures, Comparison and Categorisation, Identity, Identity Threats and Dissociation, Identity Protection). These will be discussed through the focus of transition stages and domains of student, subject and institution. The impact such processes have on participant's self-esteem will be discussed; in particular, the effects which are derived from status perceptions of the institution are examined. Analysis self-esteem effects followed from inter and intra-group comparisons with an interaction based on their perceptions of high or low social identity status of these groups. Furthermore, the dynamic of student, subject and institutional identity indicated that participants were ambivalent about their student identity while generally positive about identification with the subject. However, institutional identity emerged as the domain, which was most at risk thereby leading to identity and enhancement protection narratives.

The analysis will be presented as three broad themes. These themes displayed each of the processes already identified:

- Identity Pressures

- Social Comparison and Categorisation
- Identity threats and dissociation

- Identity Protection.

\subsection{Identity pressures}

As was predicted transition was a time of vulnerability in which the pressure to identify was notable. However, there were some differences between first year students' experience of identification compared to third years who were about to leave university.

With the initial transition to university, students reflected how they had initially found it hard to leave behind their previous friendship group and develop a sense of belonging and identity with new peer group. Added to this a few mentioned "pressure from work", "fear of not fitting in" and "having felt uncomfortable" prior to the start of their degrees. Peel [27] proposed that students had naive images of university prior to the commencing degree study with the result of increased anxiety amongst prospective students [28]. A few students who did not live on campus or had returned home frequently felt that they had not yet integrated, this was especially true for Abigail:

“...like I wouldn't say I'd come here and -

like I go home every weekend um, and I

have done since I've been here cause I don't' feel - it's not that I don't feel comfortable, I just...would rather spend time with people at home than here yeah."

However, this was not universal and while almost all had mentioned struggles, the majority had settled and were enjoying student life. For some students they felt that university had allowed them to find "their identity". Past and Possible social identity struggles are seen in the quote below by Katy who struggled with balancing old friends and their new life but also mentioned that being independent had been important. She talks of her life prior to university as "you were yourself" and how at university "everything changed"

"no I think um I think just before um like you were conformable with the friends you had and you were them and like you were yourself kind of but before you came to uni like think everything changed and I was a more independent when I came here because I wasn't relying on anybody"

As can be seen for Katy life was thrown into flux at the changes but for one student (Tom, quoted below) the contrast between his previous life and student life had been underpinned by having to reflect on life choices

"yeah especially when you're just before uni because that's when you want to decide what you want to do for the rest of your life so it's like when you've got to make a decision on 
who you are...that's like when you make your decision"

Students had a narrative, which spoke of the tension between past identities and the desire to immerse themselves into their new identity. This was further enhanced by the need and importance of undertaking degree study, as can be seen with Tom above. Once a cognitive decision had been made to study at degree level then it was important that you made a success of it and esteem enhancement of their student identity can be evidenced by not only comparison of "self" prior to university but also of peers who had chosen not to attend Higher Education. Mikel displayed cognitive dissonance with non-university friends and his own student identity. In the first quote, Mikel highlights exposure to negative influences. However, it can also have been later in the interview he strongly identified as being a student he and had internalized the negativity to show that it he fitted into the category student:

"Mikel: yeah, not so much from family but sometimes from friends back home who like went straight into work sometimes like y'know just like a bit like, give you a bit of stick for it sort of thing

Interviewer: in what way give you stick?

Mikel: like just saying like 'our taxes are paying for you' and all that sort of thing like" "Mikel: er.. well some people say they're like, lazy and you know that they should get a job and all that sort of thing

Mikel: I um, I'd probably say I fit the stereotype quite a lot like

Interviewer: in what way?

M: um just constantly like perhaps, I blew me money on something like stupid or and err just going out a lot that sort of thing"

\subsection{Categorisation and Comparison}

Social Categorisation and Social Identity Theories allows for an understanding of the cognitive processes involved as Social Comparison occurs. The first stage of any categorisation is to develop an understanding of the social group, to do this it is necessary to establish cognitive images, as can be seen above students have images of being a student that they have internalised. The next stage is to decide how close they themselves compare to the group. Comparison of self to a group can occur by distancing themselves from the outgroup (nonstudents) while also engaging in deindividuation to establish they themselves are in fact a typical member for the social group in question. Deinviduation is a loss of self in order to merge with a larger group.

"Susan: yeah I get the same of um, my

fiancée doesn't like students

Interviewer: oh doesn't like students?
Susan: yeah,

Interviewer: you do get that actually; can you explain that a bit more?

S: 'cause they're all like, they all go out and erm, they're all like big groups of people and he thinks that he's paying for them 'cause he works and stuff

Interviewer: O.k

Susan: he's jealous

Interviewer: he's jealous?

Susan: yeah (laughs)

Interviewer: so you think people who stereotype students and are negative are jealous?

S: they were lazy in school and they just didn't get to university"

While feeling ambivalent at times about the student status the participants, as seen above, engaged in esteem enhancements to protect the student identity label.

Students differed in their identifications according to transition period (first or third year). As it was proposed the early stage of movement into higher education is characterised by categorisation and comparison, however within the third years there was evidence of a more complex social identity.

By the final year a more intricate and nuanced view of student identity and comparisons were emerging. Not all aspects of student behaviour was seen as negative and Tom talked about a list of behaviours which he perceived fits the category "student" and how he compared himself against it.

Tom “....yeah. Well I, would say like you you are a typical student ways because I have, a couple times I have sitting down going 'yes this is studenty'. Yes, yeah by living in halls, living in campus and sort of there's things you do, well I do come from the tiniest little place in the middle of nowhere which has absolutely nothing to do so even going to like a cafe and sitting down and reading books or doing sketches is being a study for me...and being quite different from how most people are back home"

The quote by Tom is an example, not only of social comparison in terms of self-categorsation with the group "student" but also social comparison with an out-group; the people back home in this case. Self-Categorisation was also evident in the words used by Alex who was a male third year student:

"I think um RMS is very important and um it's uh you know it's this idea, psychology's domain um, you know promoting um like critical thinking and scepticism and you know the concept of hypothesis testing rather than just going with your feelings or something um these values um because I assimilate these values because you know it's part of psychology 
so I guess I am assimilating a typical psychology student because of this I I identify with these values"

Alex's identity was a more complex identity than those of the first years and was focused in the quote above in the codes and behaviours he thought typical of a typical psychology student. In his own words, he was "assimilating" what he saw as Psychological values, internalizing them and then accepting this identity.

\subsection{Threats to Identity and dissociation}

An unexpected finding was how insecure the students were about their institutional identity. While the majority of students seemed to have had a positive progression a number of issues reduced their levels of identity, this occurred particularly with in domain of institution.

Two possible causes for this were identified; the first came from the external evaluation of the group. The students' own evaluation of the group was correspondingly low and therefore low attachment to the group was evidenced. Social Identity Theory has established that members of the group derive emotional self-esteem from their belonging when high value evaluations are present. As will be seen from the quotes presented below the low value from external sources resulted in low attachment to the group. A number of students cited that being a small university in a city with larger universities and the impression that the institution was not as academic was spoken about on social events amongst other students. Robin had previously attended York University.

"yeah, so many like all my friends in York are like oh my God I can't believe you go to (institution name) but like, your never do anything with your life..."

When asked if they would feel it was accurate if they were described as a typical (institution name) student distancing from the in-group was found. This is in contrast to that of general student identity as discussed in the transition section when students distanced the out-group. This distancing from their in-group indicates low attachment:

Matthew: "..um in some way yeah probably

but in ways probably not "cause it tends to get looked down a bit from like the other two unis"

Anna showed the same distancing when asked if she would introduce herself as a (institution name) Student:

“...um yeah, I don't think I'd really that I was a (intuition name) student unless asked and also if they say where do you study I would usually say in (city name), not (instuition name)."
It could be argued that a smaller university within a city that has two larger ones can be classified as a minority group.

Dissociating oneself from a social group is not unusual amongst minority groups, who often report ambivalence about their status and identity [29]. Seeking to distance from a group and affiliate to a higher status is called, within SIT, "recategorisation to a higher status." [30] Furthermore, Festinger's social comparison is seen as a dynamic within this process. Downward comparisons that further denigrate the group, in this case institution alongside upward comparisons, psychology is a higher status group, force the individual to move away from intuition identity towards that of subject. Furthermore, if stigmatisation research is incorporated then it is possible to further explain this act of dissociation through a process called "othering" in which it is argued that "the self" not includes a notion of the individual themselves but can only be fully constructed by knowing "others". "Othering" allows the individual to further compare themselves in an upward comparison to others of the same group. Brons [30] called this upward and downward comparison of in-group member to higher status groups and upward comparison of self-versus the rest of the group as sophisticated othering.

\subsection{Identity Protection Engagement}

It was interesting to note that there was one dynamic which buffered this interaction between self-esteem memberships of the institution group. The art students who lived at a small campus known as the Creative Campus and located nearer to the large city centre universities. The students talked of the culture of "being different" amongst students from the other two universities in the city, that they "were known to party". When asked if they would describe themselves as a typical (Institution Name) student Tom replied with a statement showing his self-categorisation of belonging to the in-group using "us" and "they" language.

"I think not as a (Institution Name) student, more as like the creative campus, I'm a lot more patriotic about being from the creative campus than anything else um, it seems that be more the way that I am defined, at least when you're out and stuff, 'cause the stereotypes I've heard about it, heard other peop- other students at other universities have about (Institution Name) is stereotypes of the creative campus not (Institution Name) because it, they don't' like us because we're artsy and creative."

Brewer [31] proposed that this dynamic between a minority group and larger groups "optimal distinctiveness" which postulates that individuals need to attain a balances between how distinctive 
their group from others while not risking exclusion. It further states that minority groups, contrary to previous research, can be a source of well-being and high self-esteem resulting in greater satisfaction. Furthermore, a number of researchers have explored how members of minority groups show higher identification than majority group members [32][33]. The quote above is particular interesting as Tom later went onto say that he disliked his art subject as opposed to his psychology subject "disliking how they [arts theorists] think", it can only be assumed that his high attachment was to the Creative Campus not the art subject. Additionally it is interesting to note that students were very attached to their subject identity (see quote by Anna on the previous page) while downplaying their institution label.

Hurtado and Carter [34] measured conditions that could increase a student's sense of belonging and identification, such as academic behaviours. This was confirmed by a number of students who discussed at the subject identity level that working in groups, being with other students and work that challenged them increased their identification with their subject. A few students expressed how groupwork in particular increased their identity:

Matthew "I didn't mind too

much the poster side of things it

was the start and you got to

know people a bit more because of that."

Anna: "I quite the first year it was a diff getting into groups, talking over it like going over your own experiments that sat doing an essay, doing your own individual research and the fact that you were sharing with with other people and I met more new people in that group as well so I like that assignment with the poster."

It was during these parts in all interviews that students showed a degree of pride about their chosen subject, especially with the image they felt it portrayed to out-group members. This was one of the few themes that was constant across the interviews and although not all students agreed, there was a majority consensus. Anna (quoted previously) would willingly identify as a Psychology student but would distance herself from the institutional label. Research has indicated that minority groups can increase selfesteem by showing the strong attachment to one aspect of their social identities as discussed above. Crocker and Miller [35] propose the effects of comparison by a lower status group against those that they perceive as higher status is buffeted by members also identifying with successful groups in another arena. For example, a member of a minority ethnic group supporting a successful sporting team. While this research included ethnic groups, it is proposed that the participants (members of a perceived lower status institution) identified strongly with their perceived high status subject group to buffer the effects of low status membership.

Internal self-evaluations of the subject reconfirmed their identity and this internalisation of the identity was apparent even in part of the course they disliked. Alex above had previously stated that he didn't like RMS but at the quote below shows his how it had encouraged his identification with Psychology:

"I think um RMS is very important um it's uh you know it's this idea, psychology's domain, um you know promoting um like critical thinking and scepticism an you know the concept of hypothesis testing rather than just going with your feelings or something um these values um because I assimilate these values you know know it's part of psychology, so I guess I am assimilating a typical psychology because of this, I identity with these values."

This can be explored on another level, that of the journey as a student. Cathy is a third year student and the quote is far more developed than quotes about identity with first year students. This was generally the case across all interviews with 3 rd year students expressing a high level of identity with the subject, though this was mirrored by one student in the first year who explained she had grown into the subject from semester 1 to the end of semester 2. Anna:

"I'd say I acknowledge more that I'm a psychology student now at the of the year also at the beginning of the year as I going in and like introducing myself to everyone and finding my lectures, when in the middle I would maybe not acknowledge it as much"

Before moving on to summarise the research it is worth nothing that additional to the strategies outlined above students also found that taking part in extra-curricular team based activities such as playing sports on behalf of the university or working with the SU also had a buffering effect. However, this was not as strong as some other aspects and is not widely engaged with by students. Nonetheless this has been well documented finding in school and university engagement [36]

\section{Conclusion}

The data indicated that while students had negative external influences about two of the possible social identity groups, that of student and institution, they had different effects on the students categorising and comparison behavior. With student identity they engaged in distancing themselves from the out-group (non-students), however from the social group of institution they actively distanced themselves from the in-group. This is made even more interesting when we consider that the 
participants readily accepted the negative comments of the out-group about the student identity, acknowledging this typified them as students themselves. However, the institution label led to dissociated and was less obviously internalized. This is best explained by moving outside of social identity theory slightly and using "othering" processes to explain this dual aspect to categorisation. Indeed, students were found to hide behind their subject identity, enhancing that identity to overcome what could be seen as deficiencies in the broader institution.

A further possible explanation for the difference in acceptance of student or institutional identity is the external information regarding each of these social groups. For example, the cultural information for institutions is that of quantitative ratings as discussed in the introduction (i.e. NSS and league tables). However, student identity has a narrative, which talks about a rite of passage for young adults into adulthood. This narrative allows for the student behavior identified in this article such as drinking and laziness as a period of testing boundaries. The institutional identity is that of worth bound up in future objectives and expectations. Further research should consider whether differences in transitional groups could further explore the role of cultural norms attached to possible student identities.

Perceived low status institutions should acknowledge that students may be exposed to external negative evaluations. However, this study indicated that it is possible to overcome these by strong subject identities in which students were given opportunities to engage academically with each other. Furthermore, it is possible for smaller subgroups of students who felt that they had a unique identity to rebuff the external negative influences and comparisons of the larger institutions.

In order to fully understand the dynamics, further research is required, which explores the identity patterns of students attending traditional and large universities. Future research should also consider the impact of identity patterns on attainment levels.

\section{References}

[1] Chowdry, H., Crawford, C., Dearden, L., Goodman, A. and Vignoles, A., (2013). Widening participation in higher education: analysis using linked administrative data. Journal of the Royal Statistical Society: Series A (Statistics in Society), 176(2), pp.431-457.

[2] Kettley, N., (2007). The past, present and future of widening participation research. British Journal of Sociology of Education, 28(3), pp.333-347.

[3] Universities, U.K., (2013). Patterns and trends in UK higher education 2013.
[4] Baker, S. and Brown, B., (2007). Images of excellence: constructions of institutional prestige and reflections in the university choice process. British Journal of Sociology of Education, 28(3), pp.377-391.

[5] Gibbons, S., Neumayer, E., \& Perkins, R., (2015). Student satisfaction, league tables and university applications: Evidence from Britain. Economics of Education Review, 48, 148-164.

[6] Christie, H., (2009). Emotional journeys: Young people and transitions to university. British Journal of Sociology of Education, 30(2), pp.123-136.

[7] Ball, S.J., Reay, D. and David, M., (2002). 'Ethnic Choosing': minority ethnic students, social class and higher education choice. Race, ethnicity and education, 5(4), pp.333-357.

[8] David, M.E., Ball, S.J., Davies, J. and Reay, D., (2003). Gender issues in parental involvement in student choices of higher education. Gender and Education, 15(1), pp.2136.

[9] Festinger, L., (1954). A theory of social comparison processes. Human relations, 7(2), pp.117-140.

[10] Hogg, M.A., (2006). Social identity theory. Contemporary social psychological theories, 13, pp.111-1369.

[11] Turner, J.C. and Oakes, P.J., (1986). The significance of the social identity concept for social psychology with reference to individualism, interactionism and social influence. British Journal of Social Psychology, 25(3), pp.237-252.

[12] Cinnirella, M., (1998). Exploring temporal aspects of social identity: the concept of possible social identities. European Journal of Social Psychology, 28(2), pp.227-248.

[13] Symonds, J.E. and Galton, M., (2014). Moving to the next school at age 10-14 years: an international review of psychological development at school transition. Review of Education, 2(1), pp.1-27.

[14] Feldman, R.S. ed., (2005). Improving the first year of college: Research and practice. Psychology Press.

[15] Reason, R.D., Terenzini, P.T. and Domingo, R.J., (2006). First Things First: Developing Academic Competence in the First Year of College*. Research in Higher Education, 47(2), pp.149-175.

[16] Shim, S.S. and Ryan, A.M., (2012). What do students want socially when they arrive at college? Implications of social achievement goals for social behaviors and adjustment during the first semester of college. Motivation and Emotion, 36(4), pp.504-515.

[17] Krause, K.L. and Coates, H., (2008). Students' engagement in first-year university. Assessment \& Evaluation in Higher Education, 33(5), pp.493-505. 
[18] Goffman, E., (2009). Stigma: Notes on the management of spoiled identity. Simon and Schuster.

[19] Major, B. and O'Brien, L.T., (2005). The social psychology of stigma. Annu. Rev. Psychol., 56, pp.393421.

[20] Kidd, P.S. and Parshall, M.B., (2000). Getting the focus and the group: enhancing analytical rigor in focus group research. Qualitative health research, 10(3), pp.293308.

[20] Gorodzeisky, A., (2011). Focus groups as a tool in the construction of questionnaires: the case of discriminatory attitudes. Quality \& Quantity,45(6), pp.1217-1231.

[21] Vaughn, S., Schumm, J.S. and Sinagub, J.M., (1996). Focus group interviews in education and psychology. Sage.

[22] Karasawa, M., (1991). Toward an assessment of social identity: The structure of group identification and its effects on in-group evaluations. British Journal of Social Psychology, 30(4), pp.293-307.

[23] Braun, V. and Clarke, V., (2006). Using thematic analysis in Psychology. Qualitative research in psychology, 3(2), pp.77-101.

[24] Hayes, N., (1997). Theory-led thematic analysis: Social identification in small companies.

[25] Yukhymenko, M., Brown, S.W., Lawless, K., Brodowinska, K. and Mullin, G., (2014). Thematic Analysis of Teacher Instructional Practices and Student Responses in Middle School Classrooms with ProblemBased Learning Environment. Global Education Review, 1(3).

[26] Fereday, J. and Muir-Cochrane, E., (2008). Demonstrating rigor using thematic analysis: A hybrid approach of inductive and deductive coding and theme development. International journal of qualitative methods, 5(1), pp.80-92.

[27] Peel, M., (2000). Nobody cares': The challenge of isolation in school to university transition. Journal of Institutional Research, 9(1), pp.22-34.

[28] Tognoli, J., (2003). Leaving home: Homesickness, place attachment, and transition among residential college students. Journal of College Student Psychotherapy, 18(1), pp.35-48.

[29] Tajfel, J C., (1986). The social identity theory of intergroup behavior.Psychology of Intergroup Relations. Nelson-Hall, Chicago. Págs, pp.7-24.

[30] Brons, L.L., (2015). Othering, an analysis. Transience, 6(1), pp.69-90.

[31] Brewer, M.B., (1991). The social self: On being the same and different at the same time. Personality and social psychology bulletin, 17(5), pp.475-482.
[32] Ellemers, N. and Van Rijswijk, W., (1997). Identity needs versus social opportunities: The use of group-level and individual-level identity management strategies. Social psychology quarterly, pp.52-65.

[33] Simon, B. and Hamilton, D.L., (1994). Selfstereotyping and social context: The effects of relative ingroup size and in-group status. Journal of Personality and Social Psychology, 66(4), p.699.

[34] Hurtado, S. and Carter, D.F., (1997). Effects of college transition and perceptions of the campus racial climate on Latino college students' sense of belonging. Sociology of education, pp.324-345.

[35] Blanton, H., Crocker, J. and Miller, D.T., (2000). The effects of in-group versus out-group social comparison on self-esteem in the context of a negative stereotype. Journal of Experimental Social Psychology, 36(5), pp.519-530.

[36] Kort-Butler, L.A. and Hagewen, K.J., (2011). Schoolbased extracurricular activity involvement and adolescent self-esteem: A growth-curve analysis. Journal of youth and adolescence, 40(5), pp.568-581. 